\title{
Arctic Studies Exchange between Chinese and Russian Universities (by the example of North-Eastern Federal University of Russia and Chinese Heilongjiang University)
}

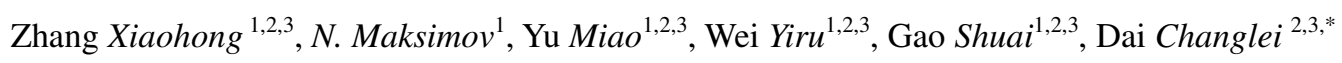 \\ ${ }^{1}$ North-Eastern Federal University named after M.K. Ammosov, 677000, 58 Belinsky str., Yakutsk (Republic of Sakha), Russian \\ Federation \\ ${ }^{2}$ University of Heilongjiang, Groundwater Institute in Cold Regions, 150080, No. 74, Xuefu str., Harbin, China \\ ${ }^{3}$ University of Heilongiiang, Joint Laboratory of Hydrology and Hydraulic Engineering in Cold Regions between Melnikov \\ Permafrost Institute SB RAS and Heilongjiang University, 150080, No. 74, Xuefu str., Harbin, China
}

\begin{abstract}
The Arctic is a unique region. It has recently attracted attention of the North Pacific countries. Its growing economy, transport, logistics and economic potential have formed a solid basis for the international cooperation. Scientists and experts from all over the world are studying the extensive natural potential of the ocean and seabed, as well as the possibility of using the route across the Arctic Ocean. In June 2019, during the visit of Chinese President Xi Jinping to Russia, both leaders of the countries, Vladimir Putin and Xi Jinping, announced 2020 and 2021 as the Years of Chinese-Russian Innovation in Science and Technology with the main topic of Science and Innovation in Technology. Having friendly relationship and political support between the two countries, North-Eastern Federal University of Russia and Heilongjiang University of China had a fruitful exchange in the field of scientific studies. During these activities, good cooperation results have been achieved.
\end{abstract}

\section{Introduction}

China and Russia are influential global players and counties with very high technological expertise. Besides, they are each other's largest neighbors. The most promising cooperation fields between Russia and China are technological innovation. In June 2019, the two Heads, Russian President Vladimir Putin and Chinese President Xi Jinping, met in Moscow where they signed a Joint Statement of the People's Republic of China and the Russian Federation on the Development of Comprehensive Strategic Partnership for Collaboration in the new Era, according to which 2020-2021 were declared the Years of Russian-Chinese scientific, technical and innovative cooperation. Events in the field of science and technology cooperation are rich in content, including projects such as research, exhibitions and academic exchanges. A number of important results have been achieved that have a wide range of impacts. At the same time, they also promote scientific and technical cooperation and exchanges between China and Russia in the Arctic.

\section{Two Universities}

\section{1 North-Eastern Federal University}

North-Eastern Federal University (NEFU)（Figure 1.） is one of ten federal universities of the Russian Federation and the largest universal university in the northeastern region of Russia. It is located in Yakutsk, the capital of the Sakha Republic. Previously it was Yakutsk State University; the national university has a long history. The development of international cooperation is one of the key tasks of the North-Eastern Federal University. The university has established many partnerships in international cooperation, signed a number of international agreements and is actively promoting academic exchanges and research programs. The unique geographic location bordering the Arctic region prompted the establishment of the Arctic Innovation Research Center, which formed a good basis for current and future Arctic research.

\footnotetext{
*Corresponding author: daichanglei@126.com
} 


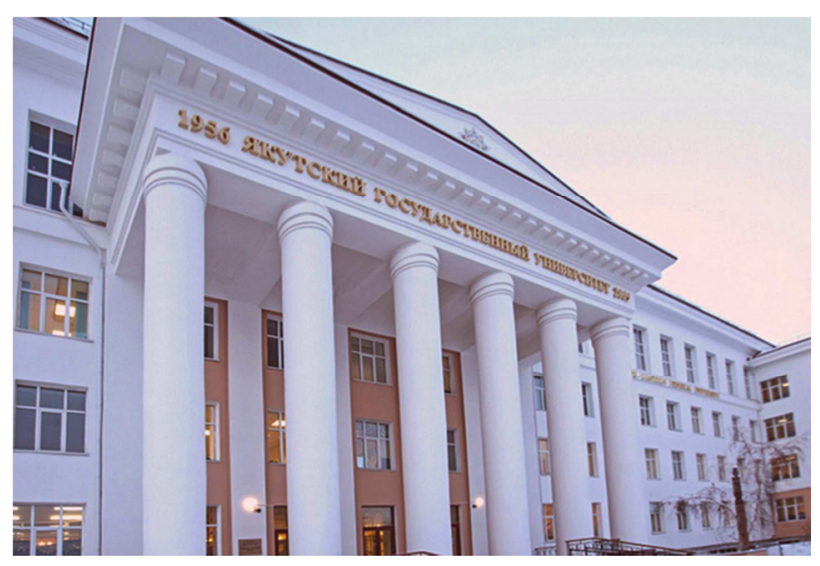

Figure 1. North-Eastern Federal University (NEFU)

\subsection{Heilongjiang University}

Heilongjiang University is located in Harbin, which is one of the northernmost cities in China close to the border with Russia. (Figure 2.)

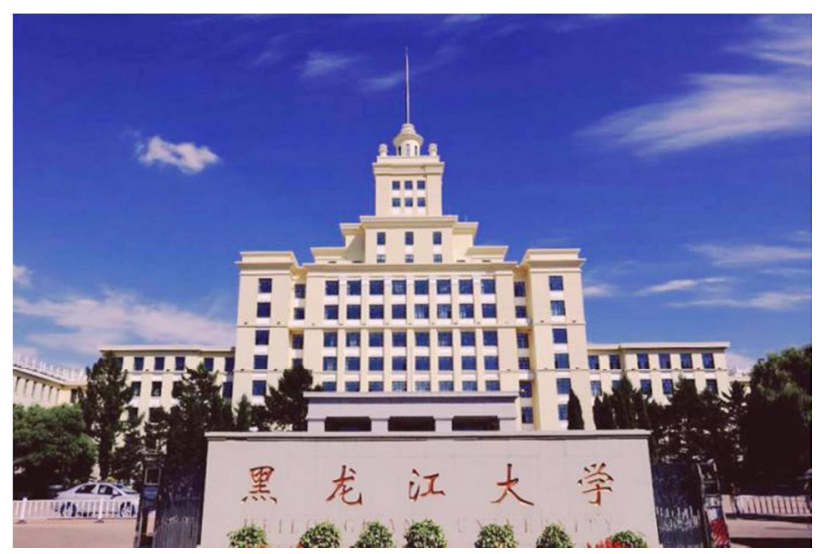

Figure 2. Heilongjiang University

The University is home to many key research bases of the Ministry of Education of China in the field of human and social sciences: Center for the Study of Russian Language, Literature and Culture; Research Center for Chinese-Russian Humanity Exchange at Heilongjiang University; Chinese-Russian Center for Comprehensive Strategic Cooperation; Provincial Center for Joint Innovation; One Belt One Road National and Regional Research Centers; Heilongjiang University National Language Promotion Base, and other research organizations.

Heilongjiang University pays great attention to the implementation of the international development strategy, adheres to bilateral international cooperation and exchange of principles of engagement and graduation, paying particular attention to the characteristics of higher educational institutions in Russia. A comprehensive and multi-level platform was developed to promote international exchange and cooperation. At present, Heilongjiang University has established close cooperation relations with more than 70 universities from 23 countries.

\section{Cooperation Content}

\subsection{Cooperation Projects}

Cooperation agreement between North-Eastern Federal University named after M.K. Ammosov (NEFU) and Heilongjiang University in the field of aquatic ecology, engineering and environment (2015); Special agreement on cooperation between Chinese University of Heilongjiang and North-Eastern Federal University of Russia in the field of Water ecology | Engineering | Environment (2019) ${ }^{[1-2]}$ (Figure 3); One Belt One Road and Ice Great Silk Road is a land river connecting water resources | environment | environmental issues, talent exchange and cooperation in the field of innovative research (2020) ${ }^{[3]}$; One Belt One Road to the Ice Silk Road, Northeast | Hydrology of the Cold Region of Asia | Climate and ecology | Ecological combination of innovative research | Talent exchange and collaboration (2021); Study of relationship between hydrological, climatic and environmental factors on the eastern route of inland rivers in the framework of the One Belt One Road and Ice Silk Road projects (in the application).

\section{中国黑龙江大学与俄罗斯东北联邦大学 在 “水生态|工程|环境” 领域 专项合作协议}

\section{COГЛАШЕНИЕ O СОТРУДНИЧЕСТВЕ МЕХДУ} СЕВEPO-ВОСТОЧНЫМ ФЕДЕРАЛЬНЬМ УНИВЕРСИТЕТОМ aserm M.A.MМОСОВА (СВфУ) ИХЭЙЛУНЦЗЯНСКИМ УНИВЕРСИТЕТОМ в сфере водвой мологии, ивкевериш и охружамовей сретs

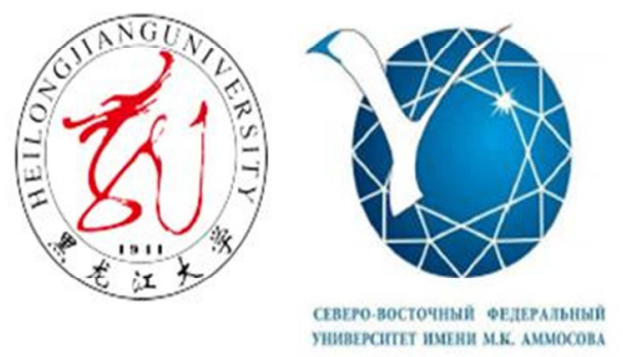

Figure 3. Special agreement on cooperation between Chinese University of Heilongjiang and North-Eastern Federal University of Russia in the field of Water ecology | Engineering | Environment (2019) 


\subsection{International Conference}

Co-organizer of the 12th symposium Water Resources in Cold Regions and Their Sustainable Use ${ }^{[4]}$ (Figure 4.5.); 4th workshop Hydrogeography of Cold Region of Asia, America and Ice Silk Road (2020) (Figure 6.); 2nd and 3rd Northern Forum on Sustainable Development by the Government of the Republic of Sakha (Yakutia), Russia, invited speaker - Professor Dai Changlei from Heilongjiang University to make relevant reports (2020, 2021); 16 October 2021 - Conference on Water in Cold Regions to be broadcast on CNKI platform sponsored by Heilongjiang University and Northeastern Federal University. At the same time, North-Eastern Federal University Vice-Rector was invited to give a corresponding report.

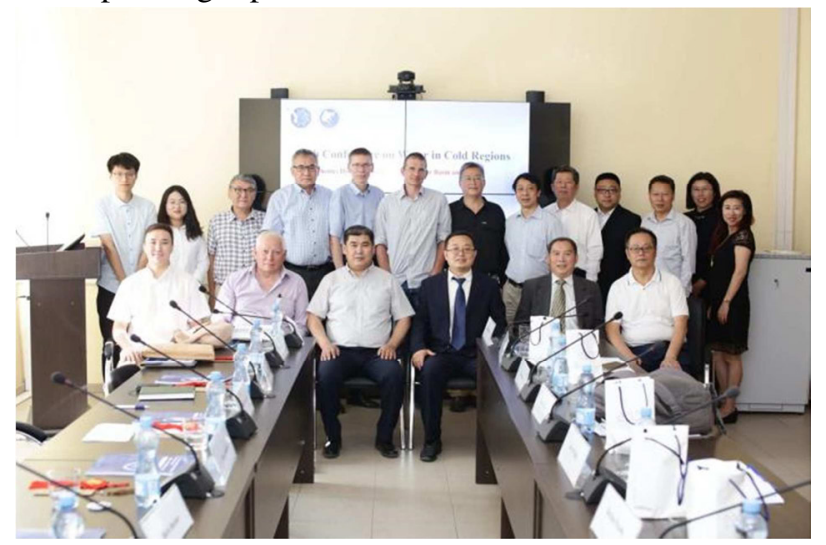

Figure 4. Co-organizer of the 12th Symposium Water Resources in Cold Regions and Their Sustainable Use

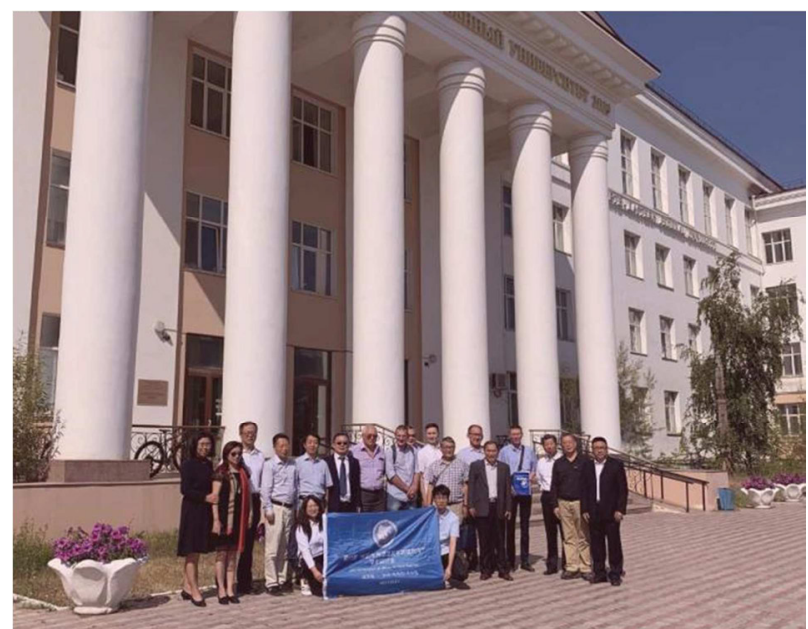

Figure 5. Co-organizer of the 12th Symposium Water Resources in Cold Regions and Their Sustainable Use

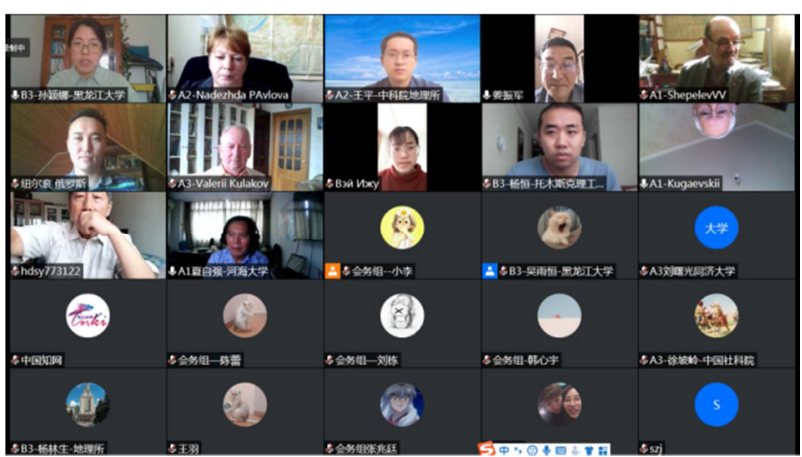

Figure 6. $4 \mathrm{t}^{\mathrm{h}}$ Workshop Hydrogeography of the Cold Region of Asia, America and Ice Silk Road (2020)

\subsection{Exchange of fellows (collaborative learning)}

In 2016, Zhang Xiaohong, studying the topic Possibility of Combined Transport from the Port of Dalian to the Arctic Ocean in Tiksi, was sent to North-Eastern Federal University under the Master's Academic Exchange Project. She took Russian language exam. In 2018, she became a $\mathrm{PhD}$ student at North-Eastern Federal University. Her scientific adviser was Anatoly Nikolaev (Figure 7).

In 2019, Yu Miao, master's degree holder from Heilongjiang University, within the framework of the project Study and Analysis of Laws of Ice Formation during Groundwater Overflow in the Alpine Regions Using the Example of Buluus Bestyakh in Siberia was sent to the North-Eastern Federal University. After that, he continued as a postgraduate student at North-Eastern Federal University of Russia with his education free of charge (Figure 7).

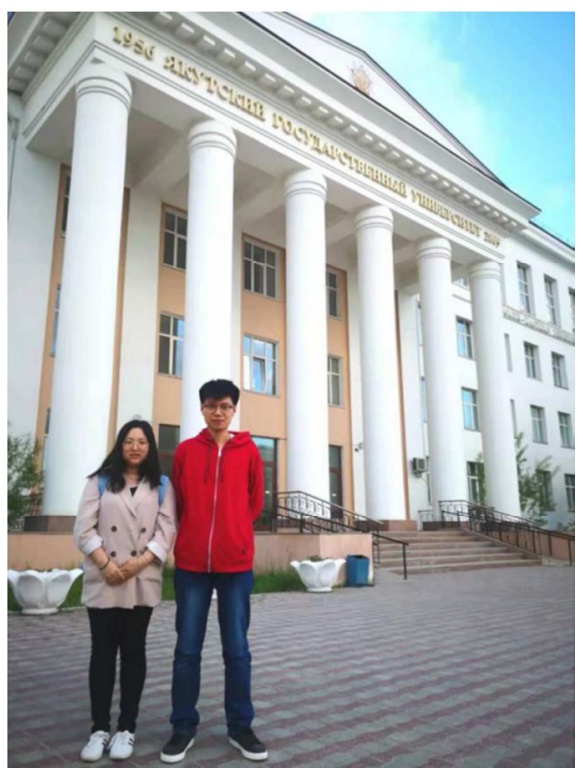

Figure 7. Zhang Xiaohong and Yu Miao from North-Eastern Federal University

At the end of 2019, Wei Yiru, master degree holder from Heilongjiang University, also joined this collaborative 
learning model. She went to North-Eastern Federal University and has become a postgraduate student (Figure 8).

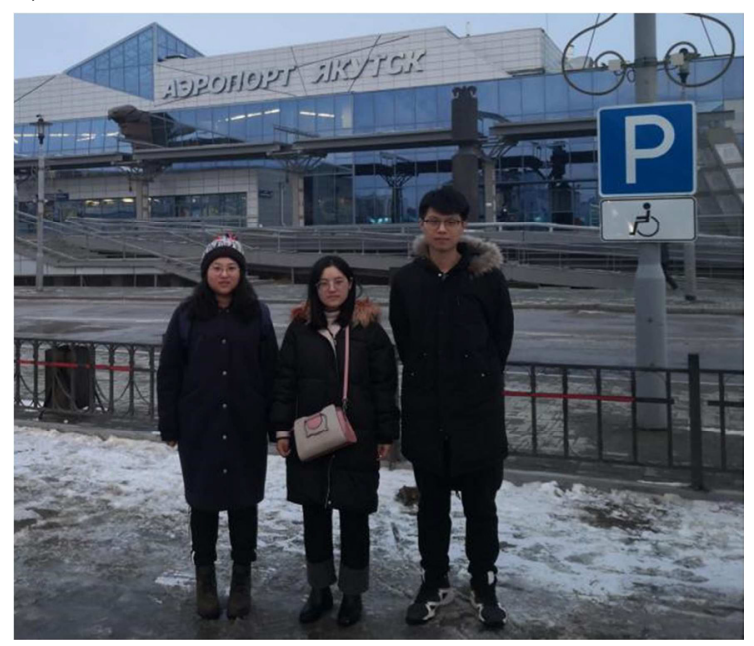

Figure 8. Zhang Xiaohong, Yu Miao and Wei Yiru in Yakutsk The fourth master student, Gao Shuai, from Heilongjiang University, is currently studying in the Preparatory Department of Graduate School at Northeastern Federal University.

\subsection{Achievements in Science and Engineering}

Two articles have been recently published in China, among them are as follows: Analysis of Regularities of Formation and Development of Thermokarst Lakes in the Central Part of the Republic of Sakha (Yakutia) ${ }^{[5]}$ (ZHANG Xiao-Hong, Anatoly Nikolaev, Alexey Kolmogorov, 2021 (Figure 9); Along the Ice Silk Road: The development of a transport network in permafrost regions in the north-east of Russia ${ }^{[6]}$ (A.A. Kugaevsky, Zhang Xiaohong, N.R. Maksimov, 2021 (Figure 10.).
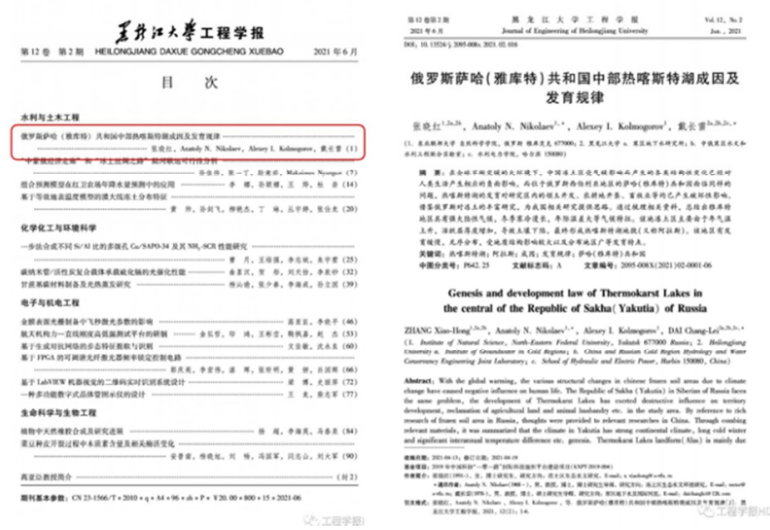

Figure 9. Analysis of Regularities of Formation and Development of Thermokarst Lakes in the Central Part of the Republic of Sakha (Yakutia)

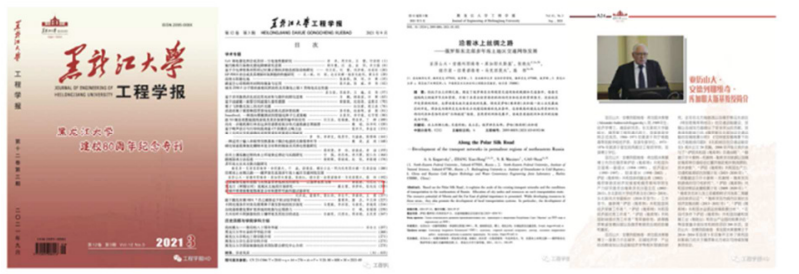

Figure 10. Along the Ice Silk Road: The development of a transport network in permafrost regions in the north-east of Russia

\section{Conclusion}

The cooperation in the fields of research and engineering between the two universities as well as scientific exchange on Arctic-related issues not only strengthened joint research between universities and scientists, but also reflected the regional importance of cooperation. China and Russia should expand cooperation in the field of scientific and technological innovation, play the role of joint laboratories and research centers, promote a two-way exchange of talented people and develop comprehensive strategic partnership and cooperation between China and Russia.

\section{References}

1. Dai Changlei, Zhang Xiaohong, Yu Miao, et al. Possibility of Combined Transport from Dalian to Tiksi, Acta Geographica Sinica, 6, 1124 (2019)

2. Sun Jiawei, Dai Changlei, Zhang Xiaohong, et al., Analysis on the Characteristics of the Watershed along the Tiksi Port from Dalian to the Arctic Ocean, Shaanxi Water Resources, 3, P. 1

3. Dai Changlei, Yu Miao, Zhang Xiaohong, et al., Simulation of slope hydrothermal process of groundwater overflow icing accumulation in Buluus, Siberia. Journal of Hydraulic Engineering, 4, 430 (2020)

4. Wei Yiru, Dai Changlei, Zhang Xiaohong, et al., Summary of the 12th conference on water resource and sustainable utilization in cold regions, Hydro science and cold zone engineering, 58 (2019)

5. Zhang Xiaohong, A.N. Nikolaev, A.I. Kolmogorov, et al., Genesis and Development Law of Thermokarst Lakes in the Central Part of the Republic of Sakha (Yakutia), Russia, Journal of Engineering of Heilongjiang University, 2, 1 (2021)

6. A.A. Kugaevsky, X.H. Zhang, N.R. Maximov, et al., Along the Ice Silk Road - the development of a transport network in permafrost regions of northeastern Russia, Journal of Engineering of Heilongjiang University, 3, 192 (2021) 